\title{
Research on Landscape Sculpture Design of Modern Zen and Tea Theme Block
}

\author{
Jiangfei Du \\ College of Urban Planning and Architecture, Southwest Minzu University, Chengdu, China \\ Email:871225313@qq.com
}

How to cite this paper: Du, J.F. (2020) Research on Landscape Sculpture Design of Modern Zen and Tea Theme Block. Open Access Library Journal, 7: e6573. https://doi.org/10.4236/oalib.1106573

Received: July 3, 2020

Accepted: July 25, 2020

Published: July 28, 2020

Copyright () 2020 by author(s) and Open Access Library Inc.

This work is licensed under the Creative Commons Attribution International License (CC BY 4.0).

http://creativecommons.org/licenses/by/4.0/

\begin{abstract}
China's Zen and tea culture has a long history and is extensive and profound. It is in urgent need of inheritance, development and promotion by contemporary people. However, how to apply Zen and tea culture to the landscape sculpture design of the block with modern methods is an important embodiment of Zen and tea culture keeping pace with the times. This paper takes the application of Zen and tea elements in the theme block landscape sculpture as the research object, focusing on the theme, interest, practicability and appreciation of Zen and tea theme block sculpture to carry out the design, in order to provide help for the design of Zen and tea theme related block landscape sculpture.
\end{abstract}

\section{Subject Areas}

Art

\section{Keywords}

Zen and Tea Culture, Theme Block, Landscape Sculpture, Modern

\section{Preface}

The landscape sculpture of Zen and tea theme blocks is an important carrier of "taking the tradition of meaning and explaining the modernity" and an important window to carry forward culture. The landscape sculpture in theme blocks is not only a display of beauty, but also a touch of integrating culture and being in it. The purpose of its design is to grasp the principle of theme and embody beauty, practicality and interest, which can not only meet the requirements of entertainment and leisure, but also feel the charm of theme block culture. Sculpture is the solidified embodiment of culture in the theme block and the 
three-dimensional display of culture throughout the whole block.

\section{Interpret the Tea Zen Culture}

Zen originated from Buddhism and is a philosophical concept and aesthetic experience. With the development of Buddhism, Zen integrated Confucianism, thought and Mohism, Family concept, etc. It includes Chinese traditional history and culture. It's the product of blending and colliding between Buddhism and Chinese traditional thoughts and greatly promotes the further development of Chinese traditional aesthetics. Besides, it has far-reaching influence on Chinese culture [1]. Zen culture is divided into tea and Zen, which blend with each other and are different from each other. Tea is one of the things, Zen is one of the hearts, and there are two kinds of methods. There is no phase, and there is no phase. Tracing back to history, the emergence and development of Zen and tea culture are closely related to the gradual prosperity of Buddhism in our country. Zen and tea were the most popular in the Tang Dynasty. Lu Yu, Cha Sheng, the one who drank tea and practiced it. His book "Tea Classics" started a new current of tea arts. While Buddhism was introduced into China and gradually localized, it formed a unique Zen culture and tea culture, which combined Zen and tea with each other and formed China's Zen and tea culture.

\section{Overview of Zen and Tea Culture Design}

Zen and tea culture is subtle and changeable, meticulous in fixed patterns. Everyone's understanding of Zen and tea culture is different. This understanding is deeply hidden in their own experience and self-restraint. Therefore, there is no specific model for reference in the landscape sculpture design of Zen and tea theme blocks. Instead, designers interpret Zen and tea culture in depth and express it shallowly. A good Zen tea theme sculpture should make the theme deeply Penetrating, full of feelings and immersive.

Tea records all kinds of tastes in life. Tea is used as a medicine to relieve inner anguish and meditation is used to smooth inner waves. People are born to attribute their life to Zen that is-“survival". A drink of tea is like a dry Zen practice. Tea is strong in Zen. Zen in tea begins with Zen. Zen in tea is intended to be simple. Simple and natural elements are extracted from Zen and tea and applied to block sculpture to increase the artistic conception of tea and Zen. In the design of Zen tea main block, we should find a fit point between Zen and tea culture and local culture to endow Zen and tea culture with regional characteristics. In the design, tea is taken as the design element, Zen Buddhism is taken as the artistic conception expression, and local cultural elements are excavated at the same time. The combination of point, line and surface is used to express the combination of block sculpture, facade and main body, "taking the tradition of meaning and explaining the modernity". The simplified form is combined with modern materials, and the combination of modernity and tradition is passed through ancient and modern times. 


\section{Modern Zen Tea Theme Block Landscape Sculpture Design Example Display}

According to the design requirements of the theme block, this paper divides the sculpture in the theme block into thematic, interesting, practical and ornamental aspects. This paper discusses with its own design examples.

\subsection{Thematic Landscape Sculpture}

Subjective landscape sculpture is the finishing touch of theme block design and an important carrier to fully display the theme of the block. In the design process, the image and intention of the theme should be fully displayed.

\subsubsection{See a New World}

The peach blossoms are flowing away. There is no other place in the world [2]. Li Bai looked at the world with a unique vision with a transcendental state of mind. In his heart, he showed the emptiness and openness of the Zen and tea culture, showing loneliness and not bowing to the world. In his eyes, there is another transcendent world. Silence. Use the stone to examine the beauty of nature and show the beauty of silence. The design USES cobblestones as the basic prototype, which is mixed and matched with resin materials, The intention is to see the big from the small, to express the meaning of mountains surrounding, climbing mountains and mountains, and to have another meaning of heaven and earth. Mountains and people merge with each other in a quiet and moving way. The joy of mountains and rivers lies in the joy of people. Create a quiet and weak Zen artistic conception (as shown in Figure 1).

\subsubsection{Su Yuan}

That is to say, the source of tea growth is traced back, implying that tea trees grow in stone crevices. The combination of stone and glass represents mountains and rivers respectively, and the combination of movement and movement, which means: high mountains and flowing water trace back the origin of rivers from high mountains, while tea trees are born in high mountains. Everything happens naturally and harmoniously, just like bitter Zen ginseng tea. Tracing back to the origin, keeping the normal heart and keeping calm (as shown in Figure 2).
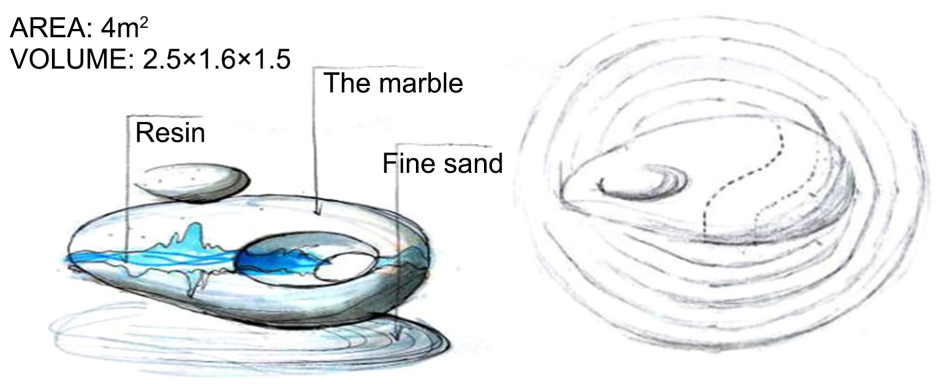

Figure 1. Hand-drawn sketch of "Another Cave" by the author (Volume: $2500 \mathrm{~mm} \times 1600 \mathrm{~mm} \times 1500 \mathrm{~mm}$ ). 


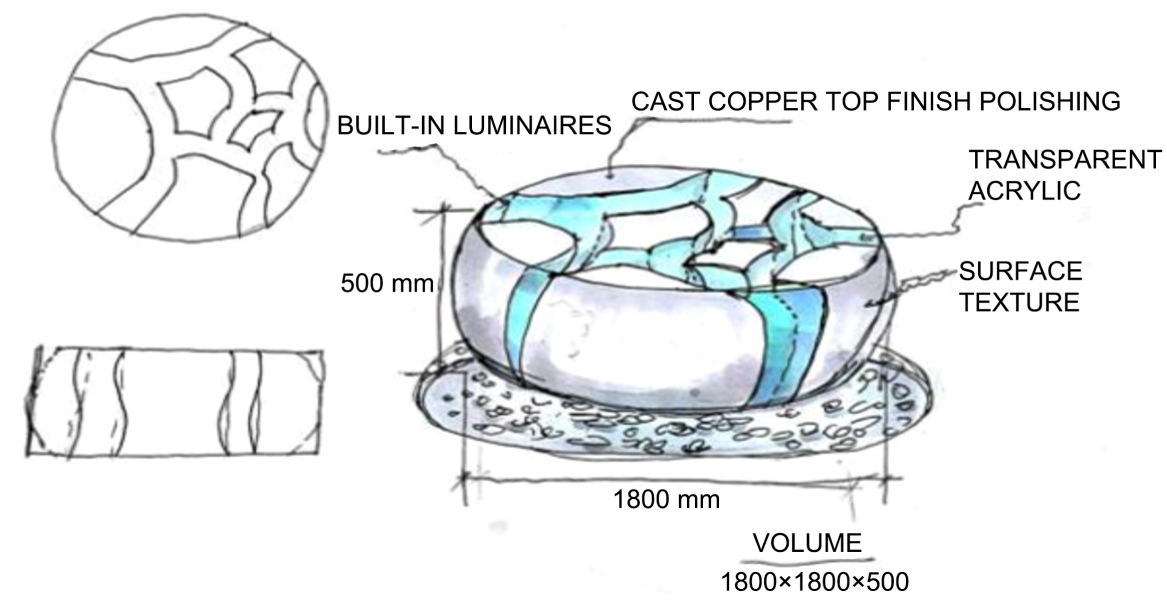

Figure 2. "Su Yuan" hand-drawn sketch by the author (Volume: $1800 \mathrm{~mm} \times 1800 \mathrm{~mm} \times$ $500 \mathrm{~mm})$.

\subsection{Interesting Landscape Sculpture}

Interesting landscape sculpture is an important window to embody theme culture in theme blocks. It is an important medium for people to interact with culture. This kind of sculpture design should not lack interest while embodying the theme culture. Let people experience the charm of culture in interaction.

\subsubsection{Three Noes}

Sculpture integrates Chinese Zen and tea culture with Confucian culture. "Three No Monkeys” is taken from Confucius' words: Don't say indecent assault, don't listen to indecent assault, don't look at indecent assault. Remind and warn yourself to be cautious and rigorous in your work and when dealing with people, and observe the "three noes" represented by these three monkeys-don't listen to what you shouldn't listen to, don't say what you shouldn't say, and don't look at what you shouldn't look at, so as to avoid right and wrong, avoid disputes, and be able to move forward steadily and rapidly. By abstracting and distorting the image of the three monkeys, the preset material is glass fiber reinforced plastic or stainless steel, and the modeling is combined in a tripartite confrontation, i.e. Stable and high safety factor (as shown in Figure 3).

\subsubsection{Joy Chair}

Four Zen and eight episodes, one Zen: joy away from the body, joy of separation, two Zen: joy of fixed life, three Zen: joy of separation, four Zen: joy of abandoning thought. The combination can be far or near, can be separated, virtual, far or near combination, unique and interesting, can rest, play, make friends, multi-functional sculpture (as shown in Figure 4).

\subsection{Practical Landscape Sculpture}

Practical landscape sculpture organically combines theme and use, and plays a dual role in the theme block, which can not only maintain the overall feeling of the block, but also assume a certain purpose in the block. 


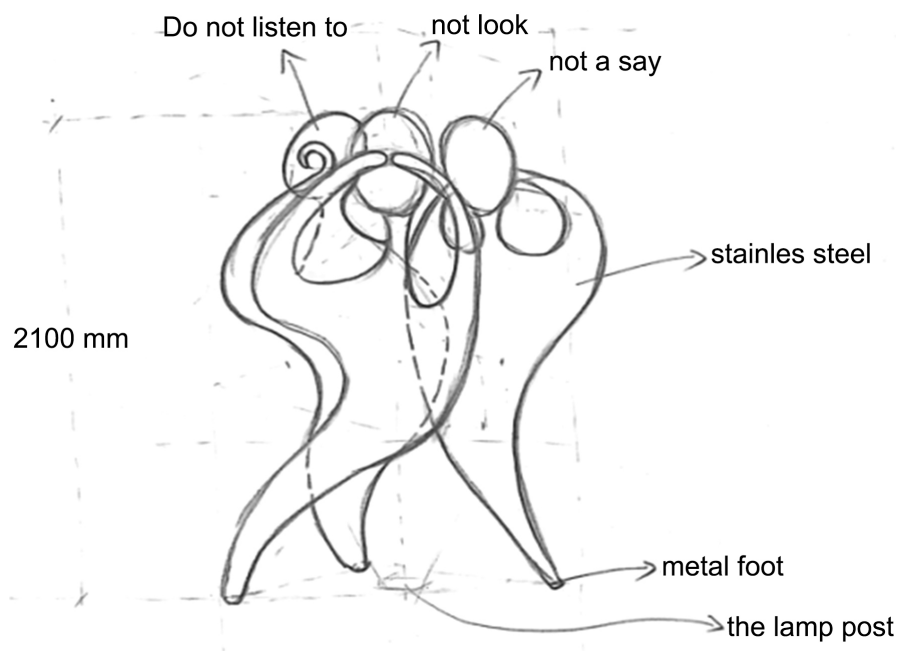

Figure 3. "Three noes" hand-drawn sketch by the author (Volume: $1300 \mathrm{~mm} \times 1200 \mathrm{~mm}$ $\times 3200 \mathrm{~mm}$ ).
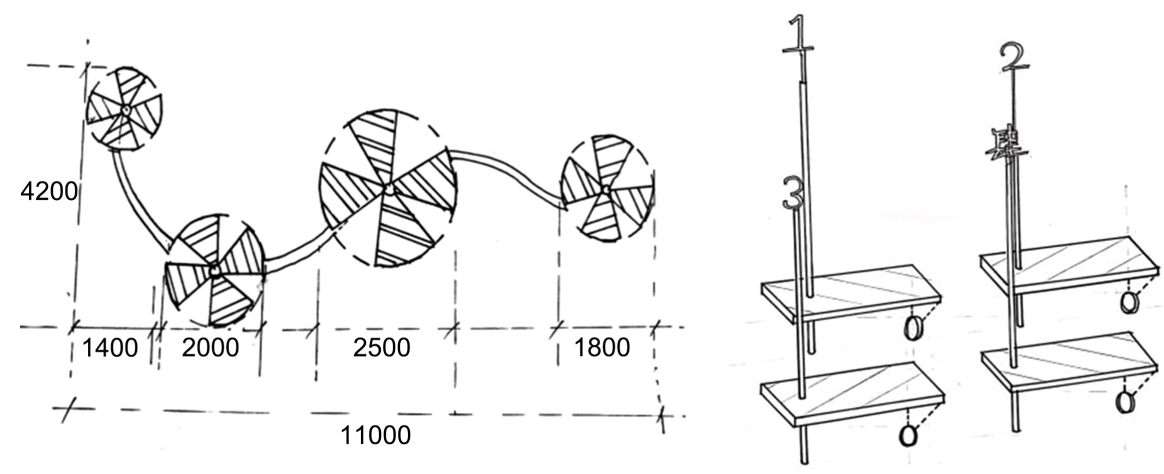

Figure 4. "Joy chair" hand-drawn sketch by the author (Volume: $950 \mathrm{~mm} \times 1400 \mathrm{~mm} \times$ $3700 \mathrm{~mm})$.

\subsubsection{The Stone and Stone Are the Opening}

"The stone and stone are the opening" Landscape lamp: the stone and stone are open, Intended to be made of natural stone, With the change of stone cracking, A copper dead tree shape is added inside to express the Zen tea artistic conception of tea trees growing in hard soil and sand. At the same time, modern construction technology is used to treat the stone crack with copper plating and acrylic lamppost with stainless steel base, making the sculpture landscape lamp simple and interesting, fully reflecting the collision between tradition and modernity (as shown in Figure 5).

\subsubsection{Zen Yue}

Landscape seat: Buddha sits on auspicious grass and realizes the truth, "Zen" communicates with "cicada": auspicious, pure and metamorphotic, "Zen" communicates with "silkworm": diligence, self-discipline and self-transcendence. The appearance of futon is wrapped with cocoon-like stainless steel hollowed-out design, which is matched with landscape trees to light up the theme of Zen tea and inherit the Millennium Zen and tea culture (as shown in Figure 6). 


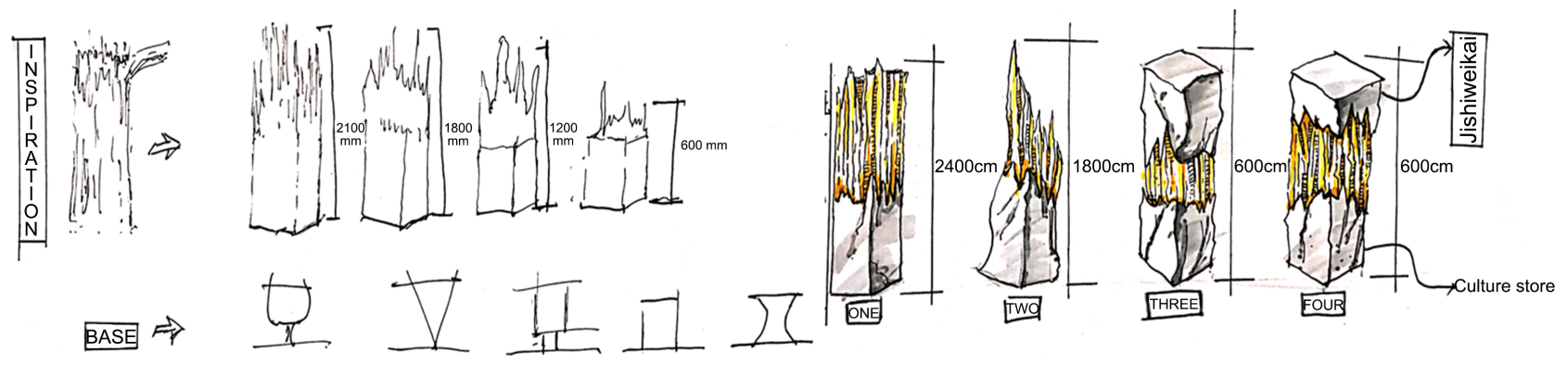

Figure 5. "The stone and stone are the opening" hand-drawn sketch by the author.
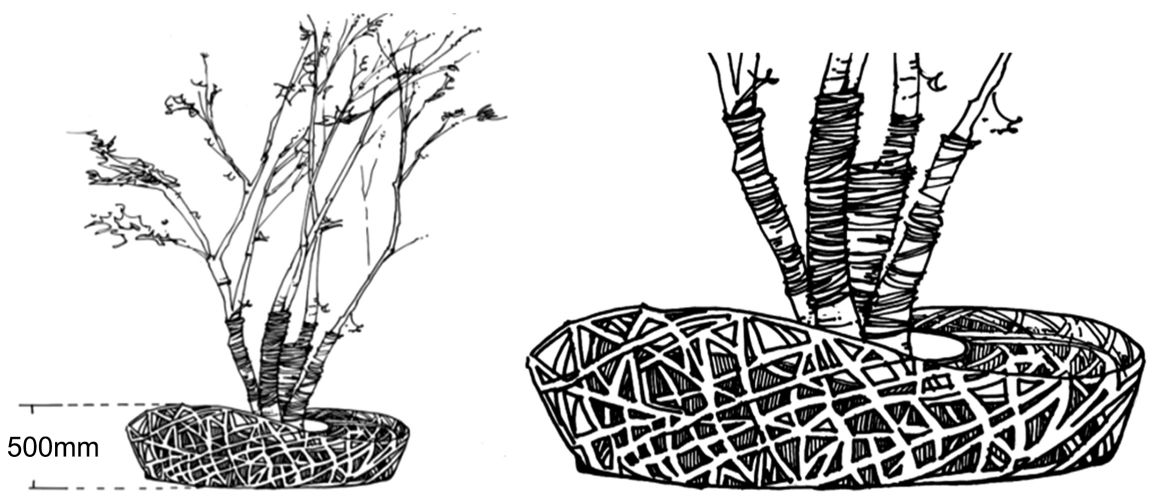

Figure 6. "Zen Yue" hand-drawn sketch by the author (Volume: $4000 \mathrm{~mm} \times 3500 \mathrm{~mm} \times$ $650 \mathrm{~mm})$.

\subsection{Ornamental Landscape Sculpture}

Although ornamental landscape sculpture is beautiful, it is not gaudy. While appreciating the aesthetic feeling of sculpture, it sets off its internal culture and sets off the theme of the block.

\subsubsection{Wrap Broken}

I save myself three times a day, meditate and cultivate one's morality, drink tea and cultivate one's nature. Zen and tea culture shows that both internal and external cultivation is the way to be human. The sculpture designed this time will sit in floating clouds, like a Buddha statue, full of infinite reverie. It is not only self-reflection, but also emptying oneself. It not only reflects the ascetic meditation of Zen and tea culture, but also reflects the infinite comfort of drinking a cup of tea (as shown in Figure 7).

\subsubsection{Tick}

Tick, tick, Take the sound of water flow, Clear and light, taking the shape of a river, endowed with sand and stone, taking the meaning of Japanese dry landscape, and decorated with herbal tea as plants, make people shine at the moment and give people a relaxed and comfortable feeling. The design is dense and harmonious. Pottery pots and stones of different heights are combined with soft lights to create an interesting and unique ornamental sculpture (as shown in Figure 8). 


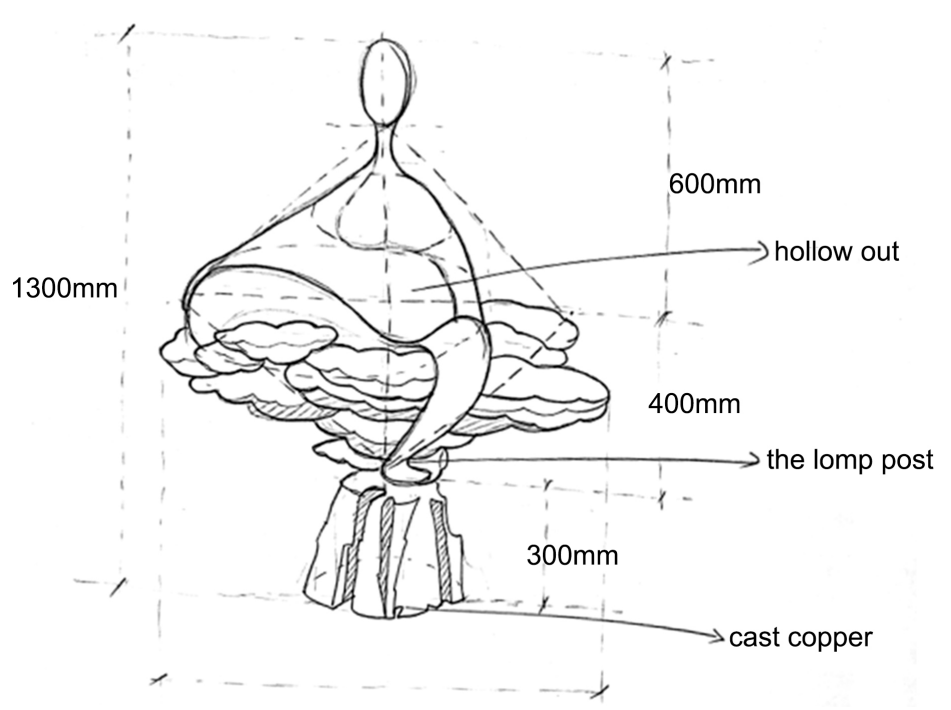

Figure 7. "Wrap broken" hand-drawn sketch by the author (Volume: $1750 \mathrm{~mm} \times 1200$ $\mathrm{mm} \times 1650 \mathrm{~mm})$.
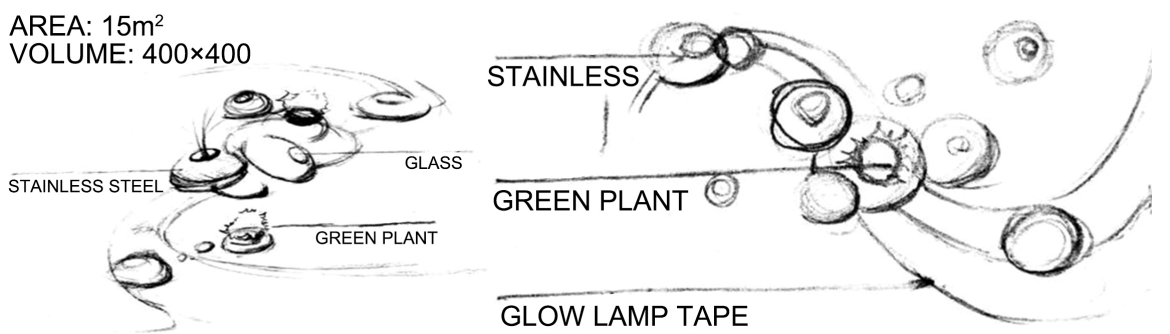

Figure 8. "Tick" hand-drawn sketch by the author (Volume: $4000 \mathrm{~mm} \times 1600 \mathrm{~mm} \times 300$ $\mathrm{mm})$.

\section{Conclusion}

Zen and tea culture is a part of Chinese traditional culture. To design landscape blocks with Zen and tea culture as the theme, it is necessary to fully tap the connotation of Zen and tea culture, combine various expression methods, and closely combine Zen and tea elements with landscape sculpture to achieve the purpose of inheriting Chinese Zen and tea culture [3]. Through the design and analysis of modern Zen-tea theme block landscape sculpture, this paper hopes to integrate Zen-tea culture and landscape sculpture with each other, and at the same time hopes that the symbiotic development of the two can bring new development vitality to the expression form of traditional culture.

\section{Conflicts of Interest}

The author declares no conflicts of interest regarding the publication of this paper.

\section{References}

[1] Yin, D.L. (2018) Research on Aesthetic Artistic Conception of Interior Design. Tea and Zen Blindly, Fujian Tea. 
[2] Li, B. (2012) Question and Answer in the Mountain. Collection of Li Taibai.

[3] Ge, X.L. and Zhang, Y.Y. (2017) Analysis of the Combination of Tea Elements and Landscape Design. Fujian Tea. 